\title{
Analysis of College Students' Mental Health and Suggestions on Crisis Prevention
}

\author{
Shaohong Chen' ${ }^{1}$, Shaomei Fang ${ }^{2}$, Shunfa He ${ }^{*}$ \\ ${ }^{1}$ Institute of Foreign Languages, Guangzhou Huashang College, Guangzhou, China \\ ${ }^{2}$ College of Mathematics and Informatics College of Software Engineering, South China Agricultural University, Guangzhou, \\ China \\ Email: *147579197@qq.com
}

How to cite this paper: Chen, S. H., Fang, S. M., \& He, S. F. (2021). Analysis of College Students' Mental Health and Suggestions on Crisis Prevention. Psychology, 12, 1982-1989.

https://doi.org/10.4236/psych.2021.1212120

Received: November 8, 2021

Accepted: December 10, 2021

Published: December 13, 2021

Copyright (c) 2021 by author(s) and Scientific Research Publishing Inc. This work is licensed under the Creative Commons Attribution International License (CC BY 4.0).

http://creativecommons.org/licenses/by/4.0/ (c) (i) Open Access

\begin{abstract}
This study investigated the psychological health of students from a private college in Guangdong for nearly a month. Self-Rating Depression Scale (SDS), interview and Solutions Statistical Package for the Social Sciences (SPSS) were used to analyze some factors such as different grade, age, gender, origin, only child in the family, etc. and to figure out whether these factors have been significant differences and associations in depression severity so as to find out the major effect factors of depression. Finally, according to the survey results and analysis, this paper puts forward some suggestions on the prevention of college students' psychological crisis.
\end{abstract}

\section{Keywords}

Private College, College Student, Psychological Health, Crisis Prevention Mechanism

\section{Introduction}

Currently, there is a strong shock and test of diversity and diversity in Chinese society's thought culture. It also has a huge impact on the learning life, thought and behavior aspects of college students in colleges, and some adverse social winds have distorted college students' psychology and made it difficult to form the right life views, worldviews and values. Changes in the overall state social environment will accelerate the pace of student growth and increase the psychological stress of college students ( $\mathrm{Wu}, 2018)$. In addition, with the rapid development of Internet in China, the learning and life of college students have been convenient, but the negative effects of the network have gradually been revealed. 
The poor culture found on the Internet, student fascination with the network, all contribute negatively to college student mental health, value orientations, and behavioral perceptions, and the fact that modern networks and some media have lost the most basic minds in the quest for benefit, overstated negative things, and students felt nervous and helpless about similar things because they lacked experience, leading to a psychological crisis (Wen, Yang, \& Xiao, 2021).

The emergence of mental health problems in college students is not only influenced by the society, but also by the native family and personal adverse habits, and the family relationship and family education are important factors affecting the mental health status of college students. In this small environment of the family, the harmonious emotions and emotions expressed by the parents in their daily life can easily affect the children, which is also a manifestation of the good family wind in the native family (Sui, 2020). Many colleges only apply psychological census for new students, but some of the psychological problems of college students result from the change of life environment, interpersonal relationships, learning methods, etc., so the psychological census in colleges needs to be expanded coverage, in order to do so better to prevent psychological crisis events.

In recent years, the suicide incidents of college students have gradually increased and their psychological health has become the focus of society. It indicates that depression is one of the major effect factors. In 2018, the Party Leadership Group of the CPC Ministry of Education issued the Guidelines for Psychological Health Education for Students in Higher Learning, which clearly pointed out that colleges and universities should expand the coverage and scientificity of psychological health assessment, enhance the ability of prevention and intervention as well as resolve the possible psychological crisis of students (Liu, 2018). In September 2020, the National Health Commission issued the Work Plan for Exploring the Characteristic Services for the Prevention and Treatment of Depression, which proposed that all high schools and universities should add depression screening into students' health examination, establish students' psychological health files, assess students' psychological status, and pay great attention to those who are with abnormal results (Fu, 2020). Therefore, it is of great significance for the work of psychological education on college students to track the psychological health of private college students, analyze their psychological status and dynamic changes, and inquire into the factors.

\section{Research Method}

\subsection{Research Subject}

The respondents of this study are college students from a private college. It adopts the method of questionnaire survey and interview. 1801 questionnaires are distributed and 1773 valid questionnaires are collected. The questionnaire is 98.45\% available and 121 students are interviewed. Of the 1773 available questionnaires, the number of males is $267,15 \%$ of the total and that of females is 
1506, $85 \%$ of the total. It includes 338 freshmen, 391 sophomores, 599 juniors and 445 seniors. Only and non-only children are 374 and 1399 respectively. And there are 929 rural students and 844 urban students.

\subsection{Research Method}

The questionnaire adopts Self-Rating Depression Scale (SDS) compiled by W. K. Zung, which is one of the scales recommended by the Department of Health, Education and Welfare (USA) for psychopharmacological research. The scale has been widely applied in some fields such as outpatient screening, emotional assessment, investigation and research due to its simplicity and visibility to reflect the subjective feelings of depression and changes during the treatment (Guo, 2012). The scale includes 20 items, which contain 2 items for psychotic-affective symptoms, 8 items for somatic disorders, 2 for psychomotor disorders, and 8 for depressive psychological disorders. Level 4 score is used for each item (no or little time $=1$ points, less time $=2$ points, considerable time $=$ 3 points, and most or all time $=4$ points). In addition, 121 students who investigated the occurrence of depressive tendency were interviewed to know the life situation, mental status, stress sources, etc., to verify whether the results were real and reliable. The study adopts SPSS22.0 for statistical analysis, descriptive statistics, Chi-square test (crossover analysis) and Pearson correlation coefficient.

\section{Result and Analysis}

\subsection{Good Psychological Health in General but Higher Risk of Depression and High Risk Depression than the National Average}

According to the Report on National Mental Health Development in China (2019-2020), 18.5\% of Chinese college students have the tendency towards depression and $4.2 \%$ have a high risk of depression in 2020 (Fu, Zhang, \& Chen, 2021). The results of the questionnaire show that among 1773 students, $21.73 \%$ of them are depressed while $4.74 \%$ are severe depression, which are both above the national average. The number of mild, moderate and severe depression students is 209, 93 and 84 respectively.

\subsection{Significant Differences of Students' Psychological Health between Different Grades}

Chi-square test (cross-analysis) is utilized to study the differences in depression severity. Table 1 shows that different grades present a 0.05 level of significance for depression severity ( $c h i=18.715, p=0.028<0.05$ ). The percentage difference indicates that seniors are $83.60 \%$ normal depression, significantly higher than the average (78.23\%) and $2.92 \%$ severe depression, significantly lower than the average $(4.74 \%)$. Therefore, compared with other grades, seniors have better psychological health. Based on the questionnaire and interviews with seniors, it 
Table 1. Chi-square test.

\begin{tabular}{|c|c|c|c|c|c|c|c|c|}
\hline \multirow{2}{*}{ Item } & \multirow{2}{*}{ Degree } & \multicolumn{4}{|c|}{ Grade (\%) } & \multirow{2}{*}{ Total } & \multirow{2}{*}{$\chi^{2}$} & \multirow{2}{*}{$p$} \\
\hline & & Freshman & Sophomore & Junior & Senior & & & \\
\hline \multirow{4}{*}{$\begin{array}{l}\text { Depression } \\
\text { Severity }\end{array}$} & Normal & $260(76.92)$ & $305(78.01)$ & $450(75.13)$ & $372(83.60)$ & $1387(78.23)$ & \multirow{5}{*}{18.715} & \multirow{5}{*}{$0.028^{*}$} \\
\hline & Mild & $42(12.43)$ & $54(13.81)$ & $72(12.02)$ & $41(9.21)$ & 209(11.79) & & \\
\hline & Moderate & $15(4.44)$ & $18(4.60)$ & $41(6.84)$ & $19(4.27)$ & $93(5.25)$ & & \\
\hline & Severe & $21(6.21)$ & $14(3.58)$ & $36(6.01)$ & $13(2.92)$ & $84(4.74)$ & & \\
\hline \multicolumn{2}{|c|}{ Total } & 338 & 391 & 599 & 445 & 1773 & & \\
\hline
\end{tabular}

${ }^{\star} p<0.05 ;{ }^{* *} p<0.01$.

is presented that compared with public universities, private college graduates have less academic pressure and most of them can graduate flawlessly. Their low employment expectations assist them in landing a suitable job, meanwhile, their good family conditions produce less economic pressure. As a result, senior students' psychological health is generally good.

On the basis of Table 1, the first and third years are the high incidence of depression. $23.08 \%$ of the freshmen have the tendency towards depression whose severe one is $6.21 \% .24 .87 \%$ of the juniors have the tendency towards depression whose severe one is $6.01 \%$. These dates are significantly above the average. After sorting out and analyzing this result, it is found that there are two main reasons for freshmen's psychological problems. Firstly, it is the discomfort to the new environment after enrollment. The first year in college is the period from dependence to independence, from family to campus. In this way, some students may result in the sense of discomfort and drop as well as a series of psychological problems because of so many changes such as changes of living environment, interpersonal relations, learning methods and so on. Those students are mainly focused on mild and moderate depression. Secondly, it is the existing psychological problems before enrollment. These students have shown obvious symptoms during high school and most of severe depression students have been diagnosed before entering school. As for the juniors, with age and increasing experience and knowledge, their ideological independence has a further development. They desire for freedom, take pleasure in expressing and become tired of parental discipline, which may easily lead to parent-child conflict. What's more, love and sexual problems begin to trouble them. Emotional instability caused by broke-up, improper interpersonal relationships with classmates and roommates are responsible for psychological problems.

\subsection{Few Impacts from Gender, Place of Origin, Only Child on Psychological Health}

From Table 2, factors such as gender, place of origin, and only child are all significant in depression severity $(p>0.05)$, thus it is indicated that college students in the same factor present consistency in psychological health and are obviously 
different. These results show that there is no need for school managers and teachers to distinguish gender, origin, only child and other factors in the process of psychological crisis prevention and health education for students.

\subsection{Younger Age, Aggravation and Concealed Mentality in Psychological Problems}

The study adopts Pearson correlation coefficient to indicate the correlation status. From Table 3, sleep disorder, feeling of emptiness in life, feeling of worthlessness and loss of interest show a significant negative correlation of 0.05 levels. It means that the younger the college students are, the poorer sleep quality and stronger sense of powerlessness and worthlessness to life will be. From Table 4, the correlation coefficient between depression severity and age is -0.059 and it presents a significant negative correlation of $p<0.05$ level. It implies that the trend of depression severity increases with age decreasing and proceed to show the younger age and aggravation in psychological problems. According to the investigation, problems of suicide in private colleges are not caused in colleges,

Table 2. Chi-square test.

\begin{tabular}{|c|c|c|c|c|c|c|c|c|}
\hline \multirow{2}{*}{ Titles } & \multirow{2}{*}{ Items } & \multicolumn{4}{|c|}{ Depression Severity } & \multirow{2}{*}{ Total } & \multirow{2}{*}{$\chi^{2}$} & \multirow{2}{*}{$p$} \\
\hline & & Normal & Mild & Moderate & Severe & & & \\
\hline \multirow{2}{*}{ Gender } & Female & 1181 & 179 & 79 & 67 & 1506 & \multirow{2}{*}{1.889} & \multirow{2}{*}{0.596} \\
\hline & Male & 206 & 30 & 14 & 17 & 267 & & \\
\hline \multirow{2}{*}{ Origin } & Rural Areas & 728 & 103 & 54 & 44 & 929 & \multirow{2}{*}{2.015} & \multirow{2}{*}{0.569} \\
\hline & Urban Areas & 659 & 106 & 39 & 40 & 844 & & \\
\hline \multirow{2}{*}{ Only Child } & Yes & 302 & 38 & 18 & 16 & 374 & \multirow{2}{*}{1.830} & \multirow{2}{*}{0.608} \\
\hline & No & 1085 & 171 & 75 & 68 & 1399 & & \\
\hline
\end{tabular}

${ }^{*} p<0.05 ;{ }^{* *} p<0.01$

Table 3. Pearson correlation coefficient.

\begin{tabular}{cc}
\hline & Age \\
\hline Sleep Disorder & $-0.053^{\star}$ \\
Feeling of Emptiness in Life & $-0.057^{\star}$ \\
Feeling of Worthlessness & $-0.053^{*}$ \\
Loss of Interest & $-0.052^{*}$ \\
\hline
\end{tabular}

${ }^{\star} p<0.05 ;{ }^{* *} p<0.01$.

Table 4. Pearson correlation coefficient.

\begin{tabular}{rc}
\hline & Depression Severity \\
\hline Age & $-0.059^{*}$ \\
\hline${ }^{*} p<0.05 ;{ }^{* *} p<0.01$. &
\end{tabular}


but in middle and high school when students' psychological problems are hidden. However, they break out in colleges. It is suggested that freshmen should conduct psychological health quality assessment and psychological abnormality screening so as for educators to timely learn the psychology of students and carry out targeted psychological crisis prevention and education work.

\subsection{Great Impact from Family Environment on Students' Psychological Health}

Problem student is often from problem family. This survey learned that more than $90 \%$ of the severely depressed students are affected by the original family, which may be a single parent, recombinant family, disharmonious parents, high expectations of their children, excessive doting and protection, lack of care or family history of mental illness. Psychoanalysis believes that human psychological problems or illness are caused by negative emotional memory in childhood, that is, the original family. This result shows that the students' psychological problems are mainly caused by the original family. Therefore, despite routine work, student managers and educators should not only pay attention to their psychology but their family, finding out the root cause of their psychological abnormalities in order to counsel students' psychology better and accordingly.

\section{Suggestion}

\subsection{Triple Reinforcement to Carry Out Psychological Health Education and Advocate a Healthy Life}

\subsubsection{Strengthen the Publicity of Psychological Health Knowledge}

Counselors can hold some activities like theme class meetings, online new media, knowledge contests and artistic activities. Every year, May 25 is the National Mental Health Day for College Students. Many schools take the Mental Health Day as an opportunity to take May as a mental health month to organize various activities. During the month of mental health, college departments can invite psychological tutors to give related education lectures to popularize mental health knowledge. Meantime, it is available to combine the characteristics of the department to organize relevant activities, such as English psychological drama, painting competition and so on.

\subsubsection{Create the Overpowering Atmosphere of Class Psychological Health}

While entering the university, students stay away from their parents and families, mainly having a group living, which accounts for the importance of class construction. In the class of solidarity, friendship and mutual assistance, students can feel the kindness from teachers and classmates. Their negative emotions will be relieved and released in such an environment, which is conducive to the psychological health of students. Therefore, counselors and head teachers should pay attention to the construction of the class collective by organizing various collective activities to create a harmonious and upward class, enhance 
study atmosphere and strengthen class culture construction. When students are put in the atmosphere of unity and mutual assistance, they will learn to care for others and also get one from others, which is helpful to reduce the impact of negative emotions. Psychological health-related activities can be organized every month to relieve their passive emotions in time. Moreover, the change of seasons will affect people's emotions, which sets requirements for counselors and head teachers to provide students relevant knowledge along with the change of seasons so that students can establish appropriate mental health awareness. Compared with high school, the way of learning in colleges has changed a lot, focusing on independent learning. Counselors and head teachers should aid students to adjust their learning methods, establish learning goals, make appropriate planning and time management as well as guide them to concentrate their time and energy on learning so that they will not pay too much attention to negative issues, benefitting students' mental health.

\subsubsection{Spread the Knowledge of Psychological Health into the Dormitory}

The school can distribute materials such as "psychological health knowledge" to each dormitory and paste them in conspicuous places in the dormitory. Thus, students not only can more objectively recognize and perceive their own emotions but solve the problems by themselves. At the same time, the counseling hotline and address of the school's service center should be posted so that students can get timely help from the school's psychological center when they encounter psychological and emotional troubles.

\section{2. "Four Early" Prevention Mechanism}

There remain the tasks of covering psychological health quality assessment as well as conducting surveys of freshman and junior students every year but spot checks and self-tests for students of other grades. To assure "early detection", counselors are expected to carry out timely interviews and psychological counseling for students with abnormal screening as well as pay special attention to students with sleep disorders, loss of interests, problems with their family of origin and a family history of mental illness. To assure "early report", counselors should turn to college leaders and teachers of the school psychological health counseling center once they are conscious of students' psychological problems. To ensure "early intervention", counselors are supposed to talk to students who are normal depression at least once a week and communicate with their parents once a month. Additionally, follow up and focus on students who are severe depression, who should be communicated with at least twice a week and whose parents should be once. And it is advised that class psychological assistants, dormitory assistants and other cadres keep attention on classmates' psychological conditions, making concerted efforts to help these students regain their mental health.

Rome was not built in a day and the same would be true of psychological crisis. For one, parents and teachers should establish a sense of psychological crisis, 
not putting their own negative emotions on students. Also, they can try to create a relaxed and peaceful atmosphere for the students as well as create a good environment for students' growth to reduce the occurrence of psychological crisis. If there has been a psychological crisis, parents, teachers and classmates should offer more care and understanding in daily life and study so that their psychological abnormalities will no longer deteriorate, ease the crisis and finally restore psychological health. For another, the school should make overall planning and coordination, establishing and improving the prevention, intervention, emergency plans and measures. Furthermore, unite the forces of various departments, promote efficient communication and keep channels open so as to form a joint force and protect the development of students.

\section{Founding}

Foundation Item: Characteristic Innovation Program of Guangdong Colleges and Universities (No: 2020WTSCX53).

Scientific Research Program of Guangzhou Huashang College (No: 2021HSQX47).

\section{Conflicts of Interest}

The authors declare no conflicts of interest regarding the publication of this paper.

\section{References}

$\mathrm{Fu}, \mathrm{J}$. (2020). Notice of the General Office of the National Health Commission on EXploring the Special Services for the Prevention and Treatment of Depression and Alzheimer's Disease. http://www.gov.cn/zhengce/zhengceku/2020-09/11/content 5542555.htm

Fu, X., Zhang, K., \& Chen, X. (2021). Blue Book of Mental Health: Report on National Mental Health Development in China (2019-2020). Social Sciences Academic Press (CHINA).

Guo, N. (2012). National Vocational Qualification Training Curriculum Psychological Consultant (Level 3). The Ethnic Publishing House.

Liu, X. (2018). Notice of the Party Leadership Group of the CPC Ministry of Education on the Issuance of the Guidelines for Psychological Health Education for Students in Higher Learning. http://www.moe.gov.cn/srcsite/A12/moe 1407/s3020/201807/t20180713 342992.html

Sui, H. (2020). The Advantage Analysis and Path Research of College Counselors Psychological Crisis Intervention on College Students. China Adult Education, No. 18, 45-47.

Wen, Z., Yang, H., \& Xiao, X. (2021). Research on the Path of Counselors to Deal with College Students' Psychological Crisis from the Perspective of Big Data. Psychological Monthly, No. 8, 227-228.

Wu, Y. (2018). Construction of Psychological Crisis Intervention Mechanism for College Students from the Perspective of Big Data. Science and Education Guide (Mid October Issue), 10, 178-180. 